\title{
Application of Geophysical Technique in the Coal Mining
}

\author{
http://dx.doi.org/10.3991/ijoe.v11i7.4759 \\ YUE Lei \\ China University of Mine \& Technology, Xuzhou, China
}

\begin{abstract}
Although coal is one of the most prevalent energy resources in the world, coal production has been a high risk industry due to its frequent accidents, especially in the developing nations. As well known, the main reason for that problem is that the potential disaster sources are not prospected before coal mining. Hence, it is very necessary to be advanced prospecting before the coal mining. Usually, the work of advanced prospecting can be done by the geophysical methods. According to the difference of disasters source physical characters, different geophysical methods can be employed. Because of different geophysical methods owning their advantages and disadvantages, this paper provides a general introduction to the most important methods used in the coal mining. These methods represent a primary tool for advanced prospecting to the disaster source. Although their main application is in prospecting disaster source in the coal mining, the methods are also used in other fields, for example, railway tunnel, environmental engineering and city construction. Consequently, geophysical method is of importance not only to geophysicists but also to geologists, engineers and archaeologists. The paper only covers the basic physical principles, methodology, and application fields of the various survey methods.
\end{abstract}

Index Terms - mining geophysics, direct current resistivity method, transient electromagnetic method, In-seam seismic method.

\section{INTRODUCTION}

The science of geophysics applies the principles of physics to the study of the Earth [1]. Geophysical surveys measure the variation of some physical quantity, with respect either to position or to time. These variations of physical quantity respond to anomalous body in earth, so these measured data can be used for analysis to study the internal distribution of physical properties so as to reveal how the physical properties of the Earth's interior vary vertically and laterally. According to the physical character of the earth, the geophysical method can be classified into electrical method, magnetic method, seismic method, geothermal method.

In fact, there are no differences between common geophysical methods and coal mining geophysical method in the principle. However, the coal mining geophysical methods are restricted in the coal mining tunnel. Besides, there are many steel belt and anchor net which bring a lot trouble for geophysical measurement and geophysical processing [2].

Hence, we will give a brief of some typical coal mining methods in order to guide choosing a method which is suitable to particular geological problem.

\section{COAL MINING GEOPHYSICAL METHOD}

\section{A. $\quad$ Direct current method}

The basic direct current method is the "equal-potential map" method in which current is passed into the ground through two groups of electrodes, which are usually approximate point electrodes far apart or line electrodes somewhat closer together [3,4]. It is customary to reverse the current periodically in order to avoid the effects of natural earth potentials and polarization. By using two exploring electrodes and a potentiometer, as shown in Fig.1 (b), equal-potential curves are located. By a comparison of these curves, the dotted line as shown in Fig. 1(a), computed for a homogeneous subsurface, is possible to locate compact bodies with resistivity different from the surrounding earth.

However, the direct current method being adopted in the coal mining tunnel to be used for advanced prospecting needs special design measurement system [5], and it is very different from the measurement system at the ground surface, as described in Fig.2. During the process of measurement, we will measure different data by adjusting the distance between $\mathbf{A}$ and $\mathbf{O}$. The distribution of electrical potential will be symmetrical for the source $\mathbf{A}$. Hence, the electrical potential in the front of heading face can be measured via measuring electrical potential in the tunnel. For example, obtaining electrical potential difference between $\mathbf{M}$ ' and $\mathbf{N}^{\prime}$ can be done by measuring electrical potential difference between $\mathbf{M}$ and $\mathbf{N}$, as shown in Figure 3.Finally, the resistivity information in the front of heading face can be calculated using the electrical potential difference $\mathbf{M}$ and $\mathbf{N}$.

Direct current resistivity method is much more reliable compared with electromagnetic methods. However, its equipment are much heavy than transient electromagnetic method. The weight and volume of equipment have to be considered in the environment of narrow tunnel.

(a)
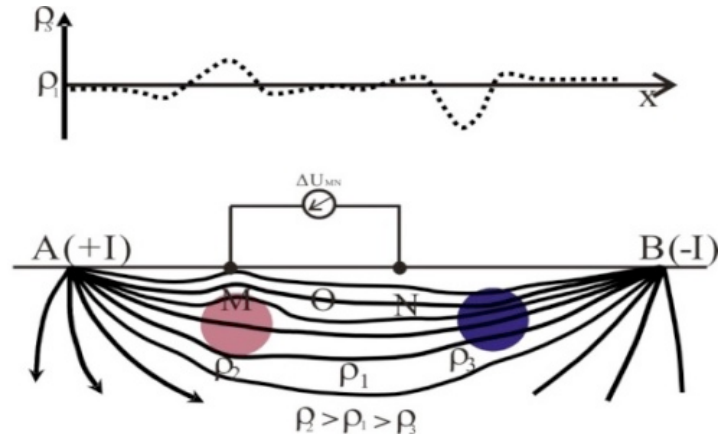

Figure 1. Principle of direct current resistivity method 
PAPER

Application of Geophysical Technique in the Coal Mining

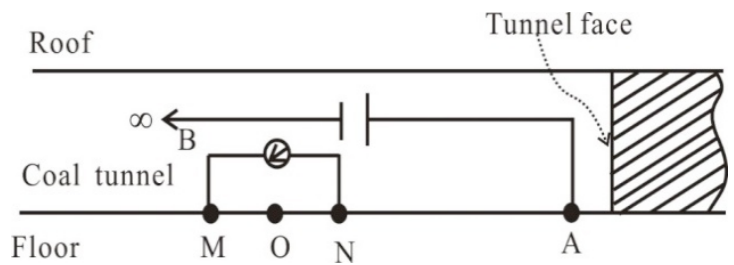

Figure 2. Measurement system of advanced prospecting using DC method in the coal mining tunnel.

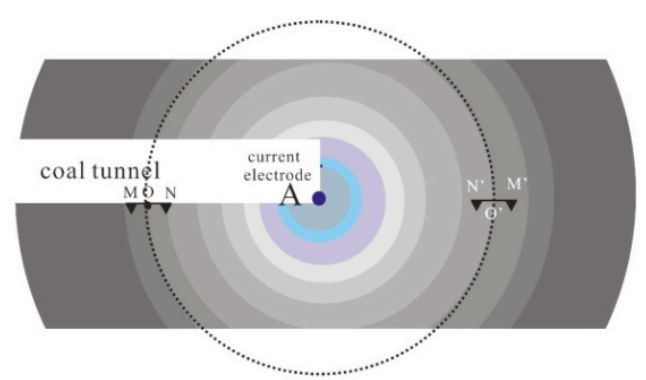

Figure 3. The contour of electrical potential in the coal tunnel.

\section{B. Transient electromagnetic method}

Transient electromagnetic, (also time-domain electromagnetic/ TEM), is a geophysical exploration technique in which electric and magnetic fields are induced by transient pulses of electric current and the subsequent decay response are measured[6,7]. TEM methods are generally able to determine subsurface electrical properties. The TEM method applies an ungrounded loop as transmitter coil. And then the current in the coil is abruptly turned off, and the rate of change of the secondary field due to the induced eddy currents in the ground is measured in the receiver coil, usually an induction coil. The primary field is therefore absent while measuring. Hence the measured data is only from the anomalous body with good conductivity.

TEM surveys are very common technique for mineral exploration, groundwater exploration, and for environmental mapping. Also, the TEM technique can be used in the tunnel in the coal mining. As well known, water inrush in the tunnel of the coal mining are the main coal potential disaster source which causes the considerable economic losses and casualties. Hence, advanced prospecting for the disaster water are very necessary. Due to the environment of the underground narrow tunnel ,TEM technique are much more suitable for advanced prospecting in the tunnel than other geophysical methods because of its portability, as shown in Fig.4.

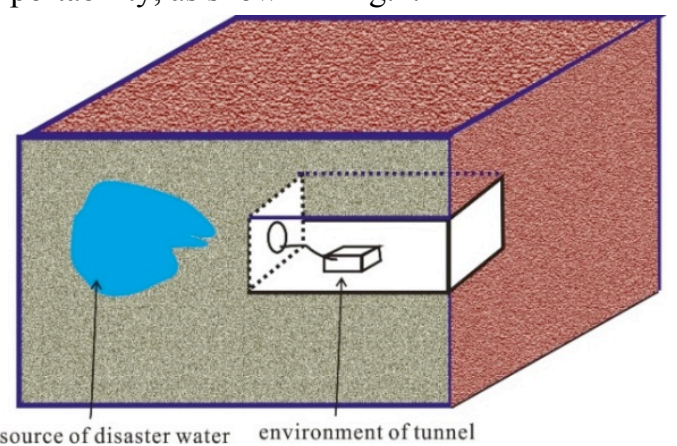

source of disaster water environment of tunnel
Figure 4. Working environment of the TEM in the underground coal mining tunnel.

During the measurement in the tunnel, the information from different directions of the heading face of the tunnel can be obtained by adjusting the prospecting direction, as shown in Fig.5. And then the distribution of resistivity in the coal layer can be analyzed using the resistivity data calculated from the measured information, as shown in Fig.6. And then apparent resistivity values calculated from the measured induced voltage of receive loops can be interpreted in terms of source of disaster water and collapse column. Finally, the geologic situation of the coal layer can be prospected before coal cutting.

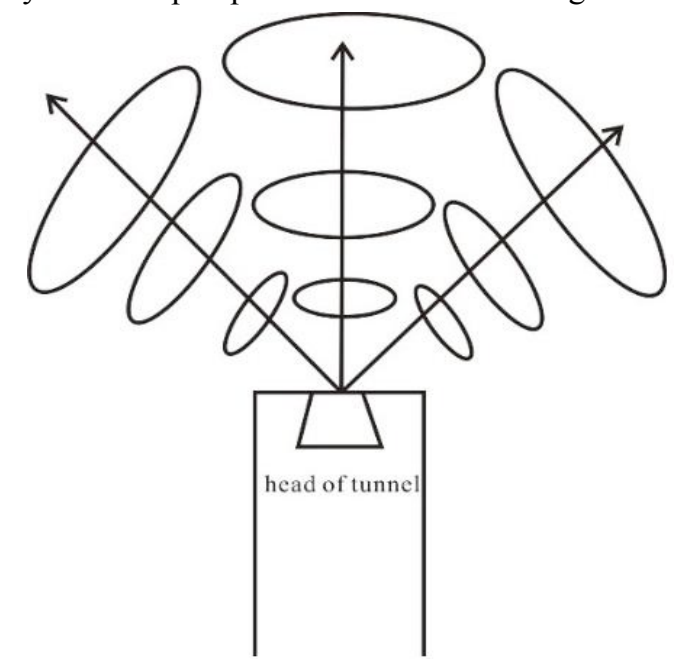

Figure 5. Schematic diagram of TEM method prospecting in underground tunnel.

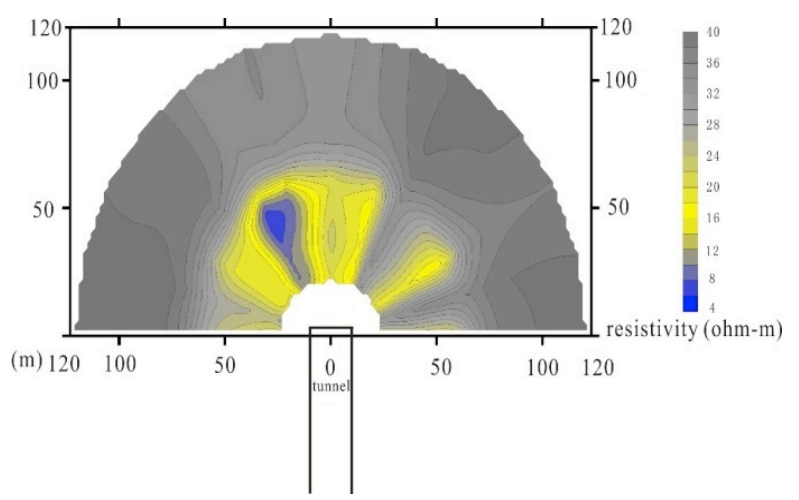

Figure 6. The distribution of apparent resistivity calculated using induced voltage from receiver loops.

\section{In-seam seismic}

A nature coal seam waveguide occours in layered sedimentary geology because the velocity of seismic waves in rocks are faster than those in coal seam.In-seam seismics(ISS) refers to the method which utilize seam waves that are trapped in the coal seam waveguide[8]. Compared with the conventional seismic technique, ISS mainly use Love wave instead of body waves. Due to the features with low speed and weak attenuation of Love wave, it will provide an adequate coverage for the area to be surveyed.Particularly, Love wave has dispersion phenomenon whichs are governed by site conditions such as seam height and geological structures and so on[9-11]. Based on above consideration, ISS surveys can be used to identify geological anomalous bodies which located in the working face and heading face.

In fact, the in-seam seismic technique involves mainly two kinds of methods, known as transmission method, as shown in Fig.7, and reflection method, as shown in Fig. 8. 
The channel waves propagating within a coal seam will be disrupted(partly transmitted and reflected) when the seam media abruptly change. The transmitted waves can be received in the opposite entry as well as the reflected waves be received along the source entry. The degree of disruption is a function of the thickness of the seam, the throw of the anomaly and the frequency of the channel wave. By dispersion analysis ,Airy phase is obtained, then the seam structure can be delineated based on the travel time and travel velocity of Love waves.

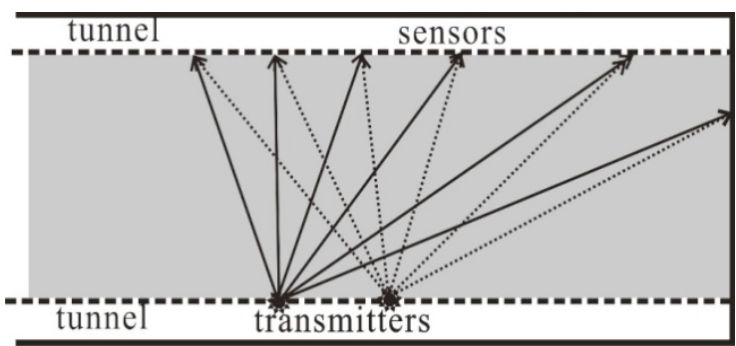

Figure 7. Schematic diagram of In-seam seismic transmission method.

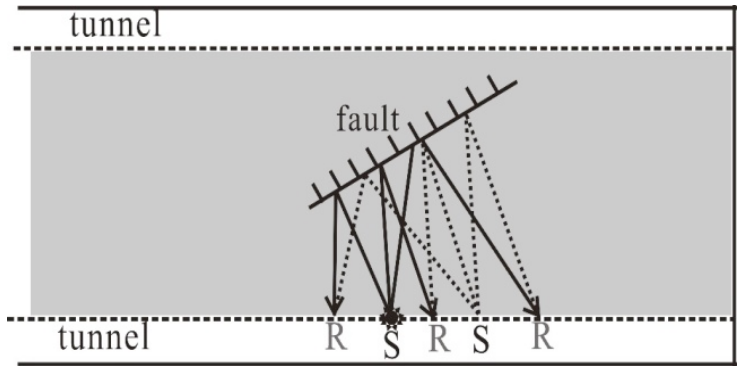

Figure 8. Schematic diagram of In-seam seismic reflection method.

\section{CONCLUSIONS}

This paper briefly introduce the gephysical methods used in the underground coal tunnel. Although the pricinple are the same between surface geophysical methods and underground geophysical mehtod, the measurement systerm are very different from each other due to very different working enviroment. Hence mature processing and interpret geophysical methods can not be directly used in the underground coal mining geophysical method. Compared with the traditonal surface geophysical methods, underground coal mining geophysical methods are in the developing situation. Also, underground mining geophysical methods are mainly used to coal miming safty production. Therefore, processing and interpret methods need to be developed, particularlyreducing the noise being from steel author and transportation belt. Besides, these geophysical methods also can be developed into monitoring techniques which differs from prospecting techniques. In the futher, the effort required to extend application of geophysical techniques to monitor accident occuring.

\section{REFERENCES}

[1] Philip Kearey, Michael Brooks and Ian Hill, An introduction to geophysical exploration-Third edition, Press of SNP Best-set Typesetter Ltd., 2002.

[2] liuShucai, Yue Jianhua and Liu zhixin, Mining geophysical exploration, Press of China University of Mining and technology, 2008.

[3] Viacheslav V. Spichak, Electromagnetic Sounding of the Earth's Interior. Press of Elsevier Science Ltd. ,2006.

[4] JinJianming, Geoelectric Field and Electrical Exploration. Press of Geological Publishing House, 1998.

[5] Huang Junge, Wang Jialin and RuanBairao, A study on advanced detection using DC resistivity method in tunnel, Chinese Journal of Geophysics, vol.49(5) pp. 1529-1538. 2006. http://dx.doi.org/10.1002/cjg2.962

[6] Hohmann G W., Three-dimensional induced polarization and electromagnetic modeling, Geophysics vol.40 pp. 309-324, 1975. http://dx.doi.org/10.1190/1.1440527

[7] Ward S H ,Hohmann G W. Electromagnetic theory for geophysical applications, In: Nabighian, M. N. , Ed. , Electromagnetic methods in applied geophysics2theory, Soc. Explor. Geophys, 1988 http://dx.doi.org/10.1190/ $1.9781560802631 . \mathrm{ch} 4$

[8] Krey T C. In-seam seismic exploration techniques[J]. Coal Exploration, vol.1, pp. 227-255, 1976.

[9] Rüter H, Schepers R. In-seam seismic methods for the detection of discontinuities applied to West German coal deposits[J]. Coal Exploration, vol.2, pp. 267-292, 1979.

[10] Klinge U J, Arnetzl H H, Krey T C, et al. Trends in the detection of coal seam discontinuities by in-seam seismic techniques[C]//3rd International Coal Exploration Symposium, Calgary, Alta, 1981.

[11] Wilson R G. In-seam seismic detection of geological structures [J]. Geoexploration, vol.24(4), pp. 295-300, 1987. http://dx.doi.org/10.1016/0016-7142(87)90003-2

\section{AUTHOR}

Yue Lei is with the China University of Mine \& Technology, Xuzhou, 221116 China. (e-mail: yuelei@cumt.edu.cn).

Submitted 25 May 2015. Published as resubmitted by the author 25 june 2015 . 